\title{
Too little for early interventions? Examining the policy-practice gap in English health visiting services and organization
}

\author{
Sarah Cowley ${ }^{1}$, Sandra Dowling ${ }^{1}$ and Woody Caan ${ }^{2}$ \\ ${ }^{1}$ School of Nursing and Midwifery, King's College London, London, UK \\ ${ }^{2}$ Department of Child and Family Health, Anglia Ruskin University, Cambridge, UK
}

\begin{abstract}
Aim: This paper explores the variable provision of English health visiting services, despite government emphasis on the need to reduce health inequalities through early interventions and provide support to families with pre-school children. Background: There is increasing evidence of the importance to later health of early child development; that is from prenatal to eight years of age. In this population group, the strongest evidence for health improvement emphasizes support for families (especially mothers) until the infant is at least two to three years of age. In the last four to five years, English government policy has focused strongly on this important life stage, particularly noting its relevance in reducing health inequalities. Simultaneously, the health visiting workforce, arguably the occupational group most closely associated with this form of work, has reduced by $10 \%$; and there is evidence of extreme variability in the way services are provided across the country. Methods: Three sources of data were analysed to discover whether the variation in health visiting services relates to need, levels of deprivation or whether other factors are influential in planning provision. The ratio of health visitors to pre-school children was mapped to indices of multiple deprivations across 144 Primary Care Trusts. Survey data were examined for evidence of links, or not, to levels of deprivation and, finally, 30 Children and Young People's Plans (CYPPs) were analysed to explore strategic planning about the distribution and type of services. Findings: Health visiting service provision appears unrelated to areas of deprivation; although, the survey data offered some evidence that individual practitioners focused efforts on the most deprived clients on their caseloads, regardless of location. At a strategic level, the CYPPs made little mention of pre-school children or their needs and offered only limited descriptions of preventive health services. Policy recommendations are made about strengthening service provision in this field.
\end{abstract}

Key words: children's services; early child development; early interventions; health inequalities; health visiting; policy-practice gap

Received: 19 November 2008; accepted: 9 March 2009

\section{Introduction}

The evidence for improved health, social and educational outcomes from a systematic approach

Correspondence to: Sarah Cowley, Professor of Community Practice Development, School of Nursing and Midwifery, King's College London, WBW-Franklin Wilkins Building, 150 Stamford Street, London SE1 8NH, UK. Email: sarah. cowley@kcl.ac.uk to supporting new parents (especially mothers) and early child development has never been stronger. Knowledge about brain and genetic development is rising at an exponential rate, with new studies all pointing to the critical period before and immediately after birth, and the first two to three years of life (Shonkoff and Phillips, 2000). Early child development (internationally defined as prenatal to eight years old) is so crucial 
to future health and health inequalities that it has been referred to as a 'powerful equalizer' (Irwin et al., 2007). This is a critical period of development, not only for its own sake (which is important), but also for tackling health inequalities (Acheson, 1998), establishing school readiness, reducing later propensity to violence and crime (Hosking and Walsh, 2005), preventing and identifying both childhood disabilities (Prime Minister's Strategy Unit, 2005) and parents' health problems, and safeguarding children during a critical period of vulnerability (HM Government (DCSF), 2008).

In England, the birth rate is rising (Office National Statistics, 2008) with one in five births being to mothers themselves born outside the United Kingdom (UK); this group has a higher risk of delivering low birth weight babies and of experiencing disadvantage in other forms (National Statistics, 2007). A government target to reduce the gap in infant mortality between the routine and manual group and the population as a whole was reviewed in 2007; 43 areas were identified that experienced a particularly high number (20 or more) of infant deaths in the routine and manual group from 2002-2004 (Department of Health (DH), 2007a).

There are increasing numbers of children with special and complex needs, including physical and learning disabilities (Prime Minister's Strategy Unit, 2005). The number of mothers experiencing postnatal depression or other mental health problems is rising (Gaynes et al., 2005). Although the number of teenage pregnancies has reduced, it remains higher in England than elsewhere in Western Europe. Also, 50\% of conceptions are in $20 \%$ of wards, and are strongly linked to factors such as low educational attainment and economic deprivation (Department for Children, Schools and Families (DCSF), 2007). The already high rates of obesity amongst British children are continuing to increase (Association of Public Health Observatories (APHO), 2006), and the need to safeguard children within families and communities is as high as ever (HM Government, 2008). Interpersonal violence associated with gangs and illicit drug use continues to be problematic, affecting family life and community safety (Bennett and Holloway, 2004). The social isolation and lack of social capital in many areas, including those where there is little deprivation, focuses attention on the need for more community development and group activities (National Statistics, 2004).

Faced with this catalogue of need, and increasing evidence of the links between health inequalities and the early years, the government has signalled a strong wish to support families, emphasizing early interventions and young children in particular (Department of Health, 2003; HM Treasury, Department for Education and Skills (DfES), 2005; 2007; HM Government, 2006a; Social Exclusion Task Force, Cabinet Office (SETF), 2007). As a professional group that has provided a universal service to British families with pre-school children since the start of the twentieth century (Dingwall, 1977), health visitors might have expected these policies to lead to an increased call for their services, but the opposite appears to be the case. There were some $15 \%$ fewer health visitors in England in 2007 (9057 whole time equivalent; WTE), than in 1988 (10680 WTE) (Health Visitors' Association (HVA), 1994; The Information Centre, 2008). The steepest fall $(10 \%)$ has occurred since 2004 , when there were 10137 WTE (The Information Centre, 2008), a period that coincides with government calls for an increased focus on the health of preschool children. This paper draws on an analysis of data from three different sources to explore this paradoxical phenomenon.

\section{Health Visiting}

In England, health visitors undertake functions similar to those of community or public health nurses in some other countries; they are qualified to understand the health needs outlined above and many more, and are skilled at delivering services that help to ameliorate them. Health visitors have always focused primarily on families with young children, and still use this base to reach out to the wider community in which children of all ages, their parents and families live, in order to influence the social determinants of health (Cowley et al., 2007). They have traditionally used the 'twin pillars of action,' home visiting and community outreach, as mechanisms for directing the service to individuals, families and communities (Cowley, 2001), varying the amount of input according to needs assessed at both an area and a personal level. There is 
increasing evidence that these approaches are effective for specific needs, and for reducing health inequalities stemming from this early period (Macleod and Nelson, 2000; Bull et al., 2004; Karoly et al., 2005; Olds, 2006).

Universal, rather than selective, health visiting services are a primary line of defence against social exclusion, since they reach out to all families with new-born babies, providing support for parents and for parenting at the most vulnerable and significant period of an infant's life (Elkan et al., 2000; Barlow and Stewart-Brown, 2003). Health visitors were the only occupational group named in Acheson's Independent Review of Inequalities in Health, which recommended that their role be strengthened (Acheson, 1998), but their services have not often been described in terms of the kind of programmes that feature in the most robust research. This is beginning to change as commissioners and service specifications increasingly identify particular programmes or funding models for delivery (Cowley, 2007a; 2007b).

\section{Variable provision}

Despite the increasing need for the service and evidence identified above, the health visiting profession has struggled to achieve its potential as a highly effective and broad based, generic public health service in England (Lowe, 2007). In particular, the service appears highly inconsistent, with variable coverage across the country (Family and Parenting Institute (FPI), 2007) and a significant fall in workforce numbers. Using the Freedom of Information Act, the FPI gathered data about the numbers of health visitors employed by each Primary Care Trust (PCT) in England, and the number of pre-school children ( $>5$ 's) for whom they had responsibility (FPI, 2007). This revealed the ratio of health visitors to children in this age group, which ranged from one health visitor to 160 children, up to one for 1355 children. These data did not indicate whether the variation was linked with area levels of deprivation.

Further evidence of variability came from a national survey of $15 \%$ of health visitors registered with the Nursing and Midwifery Council ( $n=1459$, $46 \%$ response rate), undertaken in 2005 (Cowley et al., 2007). This 'D-SCOVOR' (Determining Future Directions for Health Visiting: a Scoping Census of Health Visitor Registrants) survey revealed two broad patterns of universal service provision to mothers with new babies, one comprehensive and the other, more restricted. The comprehensive service pattern, reported by fewer than half the respondents, consisted of a package of antenatal and postnatal home visits (up to four in total) and of group and clinic based activities, such as postnatal support groups, baby massage and other community events, which new parents could attend. Respondents indicated that this universal service should meet the needs of most new parents, but if additional needs were identified, a range of services, including extra visits and specific group or community support activities, would be available. However, only $49 \%$ agreed that it was always feasible to deliver this service.

A restricted service pattern, apparent in the remaining areas, revealed a core service consisting of only one visit, 10-14 days after the new birth was notified, as well as baby clinics and child protection services. Some groups and community services were available, but they were less prevalent than in the 'comprehensive' areas. Overall, the absence of an antenatal visit predicted fewer postnatal visits; and fewer home visits predicted a smaller number of groups and community activities. In the opinion of $42 \%$, it was not always feasible to deliver this service, and most families would be unlikely to have their needs met by this restricted pattern of core services. Although additional support was said to be available once specific needs had been identified, $30 \%$ said it was not always feasible to deliver these services either.

Respondents provided some postcode data for the services they described, and analysis showed some interesting correlations and contradictions, but limited details of how provision related to areas of deprivation or other local services. These findings generated the development of the current study, which aimed to discover, nationally, whether the different approaches to health visiting service provision relate to need, levels of deprivation, availability of other services in an area or whether other factors are influential.

\section{Children's services}

There has been a recent trend towards describing services in terms of service users and health needs, rather than by professional title, for example, mental health, rather than psychiatric services. 
Accordingly, one suggestion is that health visiting services are not, after all, reducing in line with falling staff numbers, but merely changing their title. A focus on descriptions of child health services, rather than health visiting ones, would assess whether this is the case. The Children Act, 2004 stated that local authorities across England should produce a single, strategic, overarching plan for all local services for children and young people up to the age of 19, or age 25 for those leaving care (HM Government, 2006b). These Children and Young People's Plans (CYPPs) are produced, as a statutory duty, by all local authorities in England, and PCTs are required to collaborate in their development and delivery of these services. These plans were expected to address each of the five outcomes of the policy document 'Every child matters: change for children' (DfES, 2002), those being: stay safe, be healthy, enjoy and achieve, make a positive contribution and achieve economic well-being.

\section{Methods}

It is possible that the variability in health visiting service provision relates to need, levels of deprivation or the availability of other services in an area. With the advent of multi-agency planning in Children's Centres and Trusts, it is also possible that other factors may be influential. We were interested to find out:

1) whether health visiting services are configured in relation to social indicators,

2 ) if health visiting practice described in data from the survey described above (Cowley et al., 2007) varies according to areas of deprivation,

3) how preventive health services are described in local CYPPs.

Three sources of data were identified for analysis. First, data gathered by the FPI (2007) were used to analyse the ratio of health visitors to children under five years of age $(<5$ 's) against the Index of Multiple Deprivation (IMD). IMDs are intended as a measure of deprivation within small areas, so caution must be exercised when using them to reflect larger geographical areas. Also, health visiting caseloads are usually organized around 'natural areas' such as housing estates or general practitioner (GP) catchment areas, rather than the Super Output Areas (SOAs) used for IMD scores.
Second, data from the D-SCOVOR survey (Cowley et al., 2007) were re-analysed with the associated partial postcodes and IMD scores, to explore whether any rationale for the distributions could be discerned, and whether activities varied according to levels of deprivation within the area. Research ethics approval for this survey was obtained from the sponsoring university (King's College London, ref. 03/04-102, 5 July 2004).

Third, 30 CYPPs for 2006-2009 were examined to see if they provide any evidence, at the planning level, to explain the discrepancies and, apparently ad hoc development of health visiting service levels and organization. The CYPPs selected for content analysis were drawn from tables generated by data from the FPI (2007), which reported the ratio of health visitors to $<5$ 's within PCTs in England. The 10 PCTs with the highest ratio of health visitors to $<5$ 's and the 10 PCTs with the lowest numbers of health visitors to $<5$ 's were selected. A further 10 were systematically identified by selecting every tenth PCT in the rest of the list.

\section{Results}

\section{Distribution of Services}

The ratio of health visitors (WTE) to $<5$ 's was calculated from data provided to the FPI under the Freedom of Information Act, and relates to staffing levels in December 2006. Whilst this provides an average 'caseload' size for each WTE health visitor, specific team and corporate working arrangements vary from one PCT to another. There were missing data from six PCTs; two of those who supplied no information are in the most deprived quartile of areas. Figure 1 shows the rank of health visitor: pre-school child ratios sizes for the 144 PCTs that provided data (FPI Rank), against the rank of IMD scores for all 150 (IMD Rank).

Primary Care Trusts were mapped to the IMD scores in 2004 (http://www.communities.gov.uk/ archived/general-content/communities/indicesofde privation $/ 216309 /$ ) but since then PCTs have been reconfigured, often merging into larger organizations, so further mapping was carried out to 2006-2007 configurations. The averaging process created some minor anomalies similar to that found in rounding of figures. Also, since PCTs 


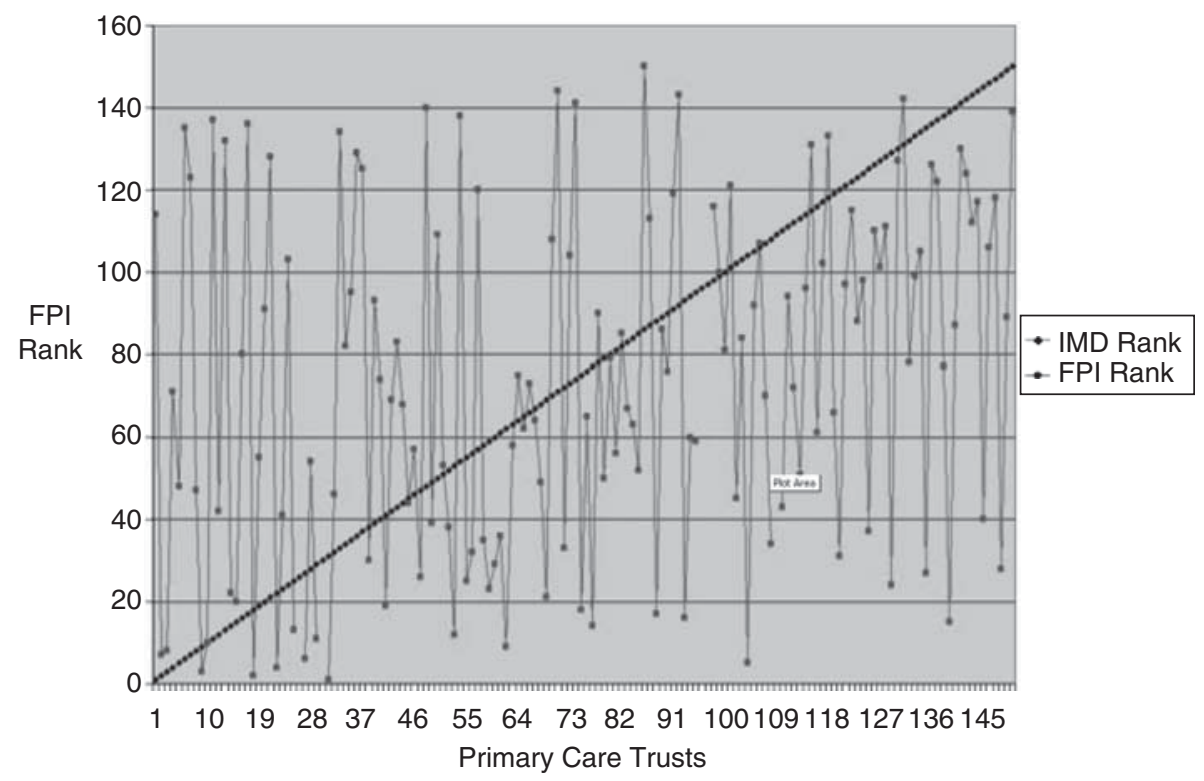

Figure 1 Rank of health visitor: pre-school child ratios (FPI Rank), against rank of IMD scores (IMD Rank)

extend across large population areas, most will encompass some areas of great deprivation and some areas of relative affluence. Detailed figures for the average score and 'best fit' of both the IMD scores and ranks of PCTs can be found in Cowley and Dowling (2007).

As shown in Figure 1, there was no apparent connection between distribution of health visiting services and levels of deprivation.

- Health visitors in 36 PCTs had full time equivalent caseloads of between 161 and 281 children under five years of age; 14 of these PCTs fell in the most deprived quartile of areas, by IMD score (between 29.31 and 49.42) and rank (between 7 and 67)

- Health visitors in 36 PCTs had full time equivalent caseloads of between 281 and 328 children under five years of age; 10 of these PCTs fell in the most deprived quartile of areas, by IMD score (between 29.3 and 48.91) and rank (between 8 and 75.75)

- Health visitors in 36 PCTs had full time equivalent caseloads of between 333 and 406 children under five years of age; eight of these PCTs fell in the most deprived quartile of areas, by IMD score (between 28.56 and 35.39) and rank (between 44 and 72)
- Health visitors in 36 PCTs had full time equivalent caseloads of between 406 and 1356 children under five years of age; 10 of these PCTs fell in the most deprived quartile of areas, by IMD score (between 30.74 and 52.16) and rank (between 3 and 62.6).

There was a strong positive rank correlation (Spearman's $\rho=+0.807, P<0.001$ ) between the number of health visitors and the number of children. The next strongest correlation between the local system measures and the IMD fields was weaker but telling: $\rho=+0.318, P<0.001$ between PCT deprivation rank and the number of children under 5. The PCTs ranked 1-30 (the 20\% most deprived) had a mean of 15089 children, and those ranked $121-150$ (the $20 \%$ least deprived) had a mean of 26166 children ( $t$-test, $P<0.001$ ). In other words, there were many more children living in areas that were not very deprived, with implications for the universal service. It would be expected that health visitors working in those areas would have less opportunity to meet many families in severe need. In turn, needy families living in such areas are harder to identify, except through a universal service.

The ratio of children to health visitors showed a smaller effect. The least deprived areas have 
rather more health visitors per child than the most deprived areas, the difference being about 67 children per health visitor (327 versus 394). This is significant at $P=0.020$ (ie, $P<0.05$ ), but the ratio varies much less than the variations in numbers of children or in deprivation. However, in 62 Spearhead Trusts, which attract somewhat greater funding to enable them to address their marked inequalities (Department of Health, 2006), there was a slight, non-significant benefit, with a ratio of 336 children per health visitor, compared with a mean of 376 elsewhere $(P=0.084 ;>0.05)$. In their responses to the FPI, many PCTs rounded the number of children to the nearest 500 or even 1000 , which tends to reduce the reliability of the calculations. Only the most significant items are reported above, because of the margin for error introduced by 'rounding' of IMD scores and ranks in mapping from their original source to PCTs.

\section{Survey data and IMD Scores}

The D-SCOVOR survey data were analysed with the associated IMD scores, to explore whether any rationale for the distribution of staff could be discerned. In these data, health visitors in the most deprived areas spent most time with homeless people (rank correlation). They were also more likely to liaise with Sure Start ( $t$-test with unequal variances, $P<0.001$, mean difference in IMD 7.3). This would match expectations, because Sure Start Local Programmes (SSLPs) were first established in the most deprived areas (Glass, 1999), which is also where most homeless people are likely to be found. This result points to some lasting benefit, where SSLPs have been established and expanded their influence in reducing health inequalities.

Those health visitors who liaise with Sure Start have significantly more frequent contact with pregnant teenagers and with pre-school children ( $U$-test, both $P<0.001)$. A small subset of the respondents $(n=47)$ had the most frequent contact (all the time) with pregnant teenagers: they worked in areas where the IMD scores are especially high ( $t$-test for this small sample, unequal variances, $P=0.009$ : mean difference in deprivation score 6.8). This group included specialists focusing solely on that (young parents) population.

Health visitors in the most deprived areas also reported spending most time on administrative work (rank correlation). This is unsurprising given the additional documentation associated with child protection procedures and with referring clients to other services such as social work or housing support. Health visitors in the most deprived areas also make the fewest types of home visit, although not necessarily the fewest visits overall. The survey only revealed data about the number of scheduled core services, not how faithfully they were carried out nor how many additional visits were made. The extent to which the respondents felt their service was likely to meet most needs on their caseload was significantly correlated with the number of scheduled home visits (more likely to be 'sufficient' if more visits are scheduled).

Neither the amount of group work nor the 'core service' items were correlated at all with deprivation scores. Where an antenatal visit was offered by the service, significantly more postnatal visits were also scheduled (median values $1 / 4$ three versus two visits; Mann-Whitney $U$-test, $P=0.001$ ). The existence of a scheduled antenatal visit was, therefore, a marker for a more comprehensive core service, but this was not related to level of deprivation ( $t$-test), nor was the presence or not of one to five postnatal visits.

In other words, service planning, set at PCT level, did not appear to take into account the need to schedule more visits or groups in deprived areas. Instead, assessments and planning of services would appear to be entirely dependent upon the professional judgement and commitment of the health visitor. Across the board, six out of ten of health visitors' most frequently reported activities were concerned with either child protection or social problems, suggesting that, regardless of locality, they spend most time with families experiencing needs associated with deprivation. Health visitors working in the most deprived areas appeared to be focusing on those families most in need, sometimes because they were employed to provide a selective service targeting vulnerable groups. However (bearing in mind resource limitations reported by respondents), once a need had been identified by the health visitor, it is quite likely that she would be unable to respond appropriately.

\section{Children and Young People's Plans}

The 30 CYPPs identified for examination were those with the 10 highest and 10 lowest ratios of 
Table 1 Children and Young People's Plans (CYPPs): size and focus

\begin{tabular}{lccccl}
\hline $\begin{array}{l}\text { Plan } \\
\text { number }\end{array}$ & $\begin{array}{l}\text { IMD } \\
\text { score }\end{array}$ & $\begin{array}{c}\text { IMD } \\
\text { rank }\end{array}$ & $\begin{array}{l}\text { Ratio HV to children } \\
<5 \text { years }\end{array}$ & $\begin{array}{l}\text { Number of } \\
\text { pages in CYPP }\end{array}$ & \begin{tabular}{l} 
Focus on/details about $<3$ year olds \\
\hline 1
\end{tabular} \\
2 & 31.98 & 54 & 160.76 & 69 & $4-6$ aspects of service provision \\
3 & 34.22 & 41 & 189.96 & 83 & $1-3$ aspects of service provision \\
4 & 41.13 & 16 & 199.94 & 84 & $1-3$ aspects of service provision \\
5 & 33.88 & 43 & 208.51 & 78 & $1-3$ aspects of service provision \\
6 & 17.41 & 176 & 217.4 & 53 & $1-3$ aspects of service provision \\
7 & 33.08 & 47 & 219.51 & 125 & $4-6$ aspects of service provision \\
8 & 46.58 & 7 & 219.62 & 36 & $1-3$ aspects of service provision \\
9 & 49.42 & 7.6 & 224.48 & 69 & $4-6$ aspects of service provision \\
10 & 25.42 & 102 & 224.79 & 115 & $1-3$ aspects of service provision \\
11 & 40.63 & 17 & 226.29 & 53 & $4-6$ aspects of service provision \\
12 & 22.94 & 118.6 & 252.96 & 96 & $1-3$ aspects of service provision \\
13 & 9.68 & 268 & 272.23 & 103 & $1-3$ aspects of service provision \\
14 & 27.4 & 87.4 & 281.69 & 44 & $1-3$ aspects of service provision \\
15 & 48.91 & 9 & 290.06 & 134 & $4-6$ aspects of service provision \\
16 & 28.87 & 103 & 303.33 & 14 & $1-3$ aspects of service provision \\
17 & 32.28 & 75.75 & 324.55 & 60 & No mention of $<3$ 's \\
18 & 11.32 & 248.4 & 343.71 & 133 & $4-6$ aspects of service provision \\
19 & 13.91 & 219 & 364.68 & 59 & $4-6$ aspects of service provision \\
20 & 13.73 & 221 & 383.18 & 40 & No mention of $<3$ 's \\
21 & 34.21 & 42 & 475.24 & 56 & Universal service /daycare only \\
22 & 44.03 & 9 & 531.47 & 77 & $1-3$ aspects of service provision \\
23 & 34.74 & 37 & 551.16 & 39 & $1-3$ aspects of service provision \\
24 & 40.43 & 18 & 565.05 & 29 & $4-6$ aspects of service provision \\
25 & 26.39 & 92 & 568.18 & 56 & Universal service/daycare only \\
26 & 7.704 & 288.2 & 570.61 & 86 & $1-3$ aspects of service provision \\
27 & 28.16 & 78 & 597.61 & 101 & $1-3$ aspects of service provision \\
28 & 23.05 & 115 & 627.89 & 37 & $1-3$ aspects of service provision \\
29 & 13.06 & 229.3 & 720.23 & 36 & $1-3$ aspects of service provision \\
30 & 19.19 & 156 & 1142.51 & 44 & $1-3$ aspects of service provision \\
& 23.39 & 111 & 1355.70 & $4-6$ aspects of service provision \\
\hline
\end{tabular}

$\mathrm{IMD}=$ index of multiple deprivation; $\mathrm{HV}=$ health visitor.

health visitors to children under five years of age, with 10 selected between these. Overall, 14 were from deprived areas, with IMD scores over 30 (range 31.98-49.42). The caseload size in these areas ranged from 160 to 565 . The remaining 16 CYPPs included areas with less deprivation (IMD range 7.70-28.87), and caseload sizes from 217 to 1355. The CYPPs were all based on the predetermined format provided by HM Government (2006b), with a wide range of interpretations. They all described a positive vision for children and young people in their locality, along with a determination to improve their outcomes and life, but there was considerable variation in content, detail, length and focus found in the plans.

The CYPPs ranged from 14-134 pages, with the detail circumscribed by the length of the document. There was some cross-referencing to other local plans and strategy documents, particularly in respect of teenage pregnancy and childhood obesity. Some areas included excerpts or appendices from these other plans, whilst others referenced them; this accounted for much of the variation. There was no great difference in length between those in the more deprived areas. As shown in Table 1 , the more deprived areas averaged 71 pages, with a range of $29-134$, whilst the less deprived ranged from 14 to 133 pages, again averaging 71 pages. As expected, the content addressed all aspects of services for children and young people; however, there was a more detailed focus on the school age population, including older teenagers. There was very much less mention of services for infants or children in the early years, with two documents making no mention of them at all, and a further two referring only to day care provision for children under three years of age. 
The majority of these CYPPs reported undertaking extensive needs assessment and a public consultation process to provide a basis for planning and development of targets around specific areas requiring attention or improvement. Although there was no consensus about the number of targets required (Figure 2) or the content of the main targets (see Table 2), increasing breast feeding featured in half the plans. Whilst these targets may relate to specific local needs, there was no obvious

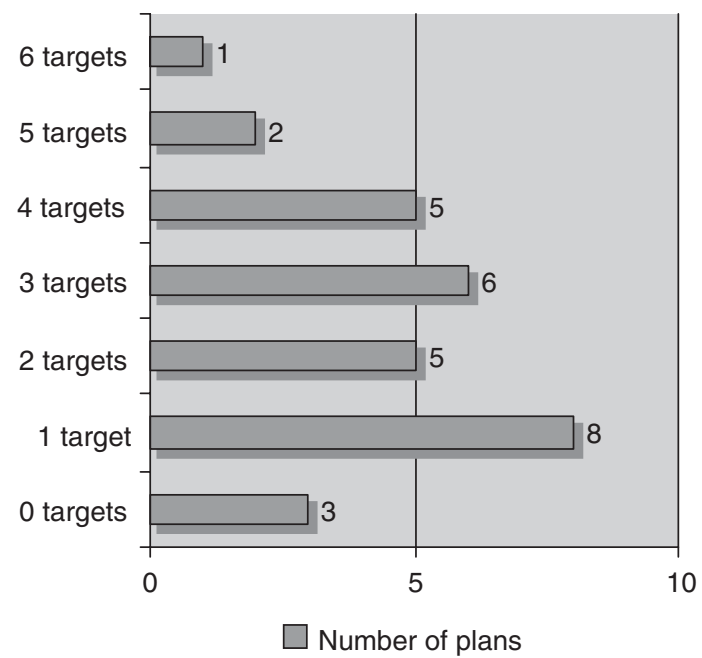

Figure 2 Number of targets identified in CYPPs link to the level of deprivation. It was disappointing, for example, that only two CYPPs in the most deprived areas prioritized smoking reduction, since maternal smoking is a major factor in low birth weight (a target in five deprived areas) and infant mortality (a target in four). There was no relationship between health visiting provision or detail in CYPPs, and whether those PCTs had 20+ infant deaths in the manual group between 2002 and 2004, as reported in the review of the infant mortality target (DH, 2007). There may be a lack of awareness, too, of the profound impact that postnatal depression can have on child development and behaviour, since only two CYPPs prioritized this aspect.

Explicit activity to achieve these targets was described in five CYPPs; three others made brief reference to other plans/policies, such as the National Service Framework or 'Birth to three matters' (Department for Education and Skills, Department of Health, 2004). The remaining 22 gave neither detail about how targets would be achieved, nor specifics about service delivery. In most instances the priorities would fall under the remit of health visiting services, for example, targets to increase uptake of immunizations, improve the support for breast feeding mothers or reduce childhood obesity; but these professionals were rarely mentioned. As indicated above, there is a trend away from naming professional groups

Table 2 Targets or priorities identified by area deprivation

\begin{tabular}{|c|c|c|c|}
\hline Targets & Frequency & $\begin{array}{l}\text { Most deprived } \\
\text { (14 CYPPs) }\end{array}$ & $\begin{array}{l}\text { Least deprived } \\
\text { (16 CYPPs) }\end{array}$ \\
\hline Increase/promote breast feeding & 16 & 9 & 7 \\
\hline Increase immunization rates & 10 & 5 & 5 \\
\hline Improve nutrition, reduce obesity & 9 & 6 & 3 \\
\hline Reduce infant mortality & 7 & 4 & 3 \\
\hline Reduce smoking & 8 & 3 & 5 \\
\hline Promote parenting skills & 6 & 3 & 3 \\
\hline Reduce low-birth weight babies & 6 & 5 & 1 \\
\hline Improve dental health & 2 & 2 & 0 \\
\hline $\begin{array}{l}\text { Reduce/support mothers with postnatal } \\
\text { depression }\end{array}$ & 2 & 1 & 1 \\
\hline Inform re: dangers of co-sleeping & 1 & 1 & 0 \\
\hline Promote road safety & 1 & 1 & 0 \\
\hline Encourage positive child development & 1 & 1 & 0 \\
\hline Deliver 'health surveillance programme' & 1 & 0 & 1 \\
\hline Health visitor to be in contact with all $<3$ 's & 1 & 0 & 1 \\
\hline Improve infant and maternal mental health & 1 & 1 & 0 \\
\hline
\end{tabular}

CYPPs $=$ Children and Young People's Plans. 
in policies and strategy documents, so this was not entirely surprising.

Indeed, six CYPPs named no occupational groups, and four mentioned some (including health visitors) only in passing. Six others described a range of professionals; in addition, eleven named teachers, the most frequently identified occupation; seven also mentioned GPs, four mentioned health visitors and one school nurses. Descriptions tended to be either very broad and abstract, or limited to a single activity, such as 'delivering child health promotion programme' or 'promoting uptake of immunizations.'

The health visiting service offers universal core and targeted interventions structured around pre-school child health promotion programme.

(CYPP3, p. 9)

The aim is to develop the public health role of health visitors to provide families with understandable, accurate information, which will encourage an informed decision to have their child immunized.

$$
\text { (CYPP30, p. 15) }
$$

Overall, 18 of the 30 plans made no mention of health visitors at all, although there were some cursory references to areas of work that might fall within their remit, for example,

Breast feeding services will be encouraged and supported.

$$
\text { (CYPP10, p. 40) }
$$

and,

Targets include an increase in breast-feeding and uptake of MMR.

$$
\text { (CYPP4, p. 7) }
$$

Most of the descriptions were sparse on information about service provision or planning. They tended to focus on the development of the Children's Centres as a resource (commonly, or at least initially, located in areas of higher relative areas of deprivation), rather than describing services that may be provided to the early years population, by health visitors or others. Areas of work likely to be undertaken by health visiting teams might be identified in one chapter of the document and then given no further attention. This applied even in areas with known high infant mortality rates. Documents that made no mention of health visiting often included only a brief reference to early years services. It does not seem, therefore, that an alternative for the descriptive term 'health visiting service' has been clearly identified.

The CYPPs all emphasized prevention, early interventions and universality, as crucial to the development of children's services. These are principles that are fundamental to health visiting, but this link was rarely made within the Plans. Four of the 30 Plans identified health-visiting practice in relation to prevention and early intervention, whilst only six offered health visiting as an example of universal services. Sixteen ascribed universal provision to other services, principally education and GP's, and eight plans made no mention of universal services at all.

Integrated, multi-agency working is highlighted across the plans, as central to improving outcomes for children, for example:

To achieve the outcomes of Every Child
Matters, agencies must work together. (CYPP 8, p. 6)

Children's Centres are commonly identified as good examples of integrated and multi-agency working and as models of service development in this direction; for example, one local authority states that:

Children's Centres are models of integrated service provision. With the co-location of different professionals the use of the Common Assessment Framework, they aim to establish matched data on looked after children and common information systems between partners.

(CYPP13, p. 33)

Many of the CYPPs identified the Children's Centres where many early years services are now located as laudable examples of the kind of service provision (namely built around multi-agency and integrated working) that local authorities are striving to design and deliver. It seems ironic that, frequently and simultaneously, they largely fail to adequately acknowledge or describe health services or other provision for the early years and $<5$ 's. In a number of instances, early years services are mentioned only as worthy examples of 
integrated service delivery, rather than acknowledging the value of these services in providing the foundation for positive health during children's growing years and into adult life.

Enormous goodwill and intentions for children and young people were evident within the CYPPs. The Plans have a common ethos underpinning the development and delivery of services for children, with reference to Children's Centres as the site of services for parents and young children. These were most positively described in one example:

Health Visitors provide home visiting and other forms of support to families under stress, they also provide advice to parents of teenagers and information to parents on all aspects of growing up. Services are provided through Children's centres, extended schools and GP practices. Nutritional programmes will be delivered through children's centres. Support for vulnerable families will also be delivered through children's centres, bringing together information, health and family support, childcare and other services for parents and children. Preventative services will be available to families within their communities through children's centres.

(CYPP22, p. 33)

However, for the most part, there was no clear rationale or description of health or early years to explain the way services are developed locally. The CYPPs provided no direct explanation for the variability of health visiting service provision. Collectively, they showed a paucity of detail, limited attention to pre-school children and apparent lack of understanding about how health visiting services might help to meet specific health needs or target health inequalities. Analysis of the documents could not determine whether this was a product of inadequate knowledge on the part of those writing the Plans, or insufficient collaboration and support from the PCTs, who are supposed to be equal partners in their development.

\section{Conclusions}

There is strong guidance from government that health inequalities are a high priority for PCTs, increasingly strong evidence that preventive services focused upon all families (especially mothers) with young children is the best known approach to reducing health inequalities, and that (in England) health visitors are the best placed occupational group to deliver this form of support. Yet health-visiting services are provided inconsistently, with patchy and underdeveloped services that are rapidly reducing in size, scope and capacity. This small study was an attempt to bring rigorous research skills to bear on three separate sources of data, which might, together, have revealed an explanation for this paradoxical phenomenon.

In the event, the analysis showed no discernible relationship between levels of service provision and indicators of multiple deprivation in an area. Analysis of the survey data suggested that, at the PCT level, little account was taken of the need to schedule more visits or groups in deprived areas. Instead, assessments and planning of services were dependent upon the professional judgement of the health visitor. At a practice level, health visitors appeared to be focusing on those families who were most in need, sometimes because they were employed to provide a selective service targeting vulnerable groups within deprived areas, and at other times in response to needs arising from social or child protection concerns.

Importantly, mention of these activities are largely absent from the CYPPs, which are supposed to be the vehicle through which all such services are organized at a strategic level. There appears to be a widespread lack of awareness of the crucial period of prenatal to three years of age as a basis for the future health and well being of all children, or for reducing health inequalities. The limited attention to this age group, regardless of levels of area deprivation, is a matter of concern. If there is little interest in pre-school children, it becomes less surprising that health visitors' role in their support is absent from the Plans. School aged children and young people are crucially important too, and were the focus of most of the CYPPs, yet only one mentioned school nurses; so perhaps it is collaboration between local authorities and the health sector that needs attention.

Since data were collected for this study, part of the former National Service Framework for Children (Department for Education and Skills, Department of Health, 2004) has been updated 
Recommendations for closing the policy-practice gap in early interventions

- Early years provision should be a mandatory part of Children and Young People's Plans

- Use the term 'infants,' as well as 'children and young people,' in policy documents to ensure this vulnerable group is not forgotten

- List universal prevention in the early years as a 'must-do' priority for the NHS

- Take account of consumer views when designing early years health services

- Require the involvement of health visitor consultants in developing Children and Young People's Plans and commissioning preventive health services

- Develop a national recommendation for the ratio of health visitors to preschool children, varied according to levels of deprivation

- Attend to the falling health visitor workforce numbers, through a drive to improve recruitment, education and retention

Figure 3 Recommendations for closing the policy-practice gap in early interventions

and developed into a new Child Health Promotion Programme (Department of Health, Department for Children, Schools and Families, 2008), focusing on pregnancy and the first five years of life. Health visitors are named as the professionals that should lead delivery of this Programme, so a review of CYPPs produced since 2008 might be more encouraging. However, there are no specific targets associated with the revised Programme, and the Public Service Agreement (PSA) targets (HM Treasury, 2007) incorporated in it (breast feeding, infant mortality and reducing health inequalities) have not changed substantially from targets in force when data were collected for this study.

Although there is an expectation that PCTs collaborate with local government in developing CYPPs, there are no specifications about the extent of involvement required, or the number of health visitors needed. The most recent operating guidance has reminded NHS organizations of their statutory responsibilities in relation to safeguarding and promoting the welfare of children (Department of Health, 2008a). Whilst this may help to raise the importance of children and prevention, measurable, short-term goals, linked to specific diseases, are still emphasized above early intervention or services providing more diffused universal prevention. Given the target-driven culture of the NHS, with only the so-called 'must-do' services being prioritized, it is unlikely that anything short of a requirement to provide a specified number of health visitors will reverse their current reduction and invisibility in the service. A ratio of health visitors per pre-school child, varied according to the extent of deprivation, could be identified and promoted as the norm.

The fall in number of health visitors has coincided with increasing government attention to the health needs of families with very young children, but also with a degree of official hostility toward health visiting as a profession. Following legislative changes, for example, the former health visiting register was closed in 2004 , with a $10 \%$ fall in their workforce occurring over the next three years (The Information Centre, 2008). The Chief Nurse has noted the need to increase health visiting numbers (Beasley, 2007), but the primary response from government to the reduction in this workforce was to draw attention to the increase in other primary care nurses (DH, 2007b). New guidance on 'transforming community services' specifically requires commissioners to avoid using professional titles, with 'health visiting services' being singled out as an example label that needs changing (Department of Health, 2008b; 2009). This study, suggests a move away from the use of the term 'health visiting services,' is being implemented already; but with no alternative descriptor, there is a tendency for this entire form of universal, preventive service provision to be omitted from the CYPPs.

Whatever the explanation, the variability is being noticed by parents, who, through their consumer groups, complain about difficulties accessing appropriate health visiting services (FPI, 2007; Russell, 2008). Furthermore, efforts directed at reducing health inequalities by attending to 
the needs of families with pre-school children will inevitably suffer, unless more consistent provision can be implemented across the country. Figure 3 summarizes some key recommendations for policy makers indicated by the results of this small study. Their implementation would be a first step towards reversing the current downward spiral and invisibility of health visiting services for preschool children and their families.

\section{Acknowledgements}

1) This paper draws on data that have previously been published as evidence by the UK Government Health Select Committee, as a 'Memorandum by Professor Sarah Cowley (HI 76) The contribution of the NHS to reducing health inequalities. House of Commons Health Committee. Health Inequalities. Written Evidence Session 2007-2008, Volume II, pages 256-261 HC 422-II' (http://www.parliament. the-stationery-office.co.uk/pa/cm200708/cmselect/ cmhealth/422/422we228.htm) Reproduced under terms of Click-use PSI license, number: C2008002077

2) The analysis was funded by a grant from the Burdett Trust for Nursing, for which we are grateful.

3) Thanks are due, too, to the Family and Parenting Institute, for allowing us to include their caseload data in the analysis.

\section{References}

Acheson, D. 1998: An independent inquiry into inequalities in health. London: The Stationery Office.

Association of Public Health Observatories (APHO). 2006: Indications of public health in the English regions, report 5: child health. APHO. Retrieved 16 December 2007 from http://www.apho.org.uk/apho/indications.htm

Barlow, J. and Stewart-Brown, S. 2003: Why a universal population-level approach to the prevention of child abuse is essential (Letter to Editor). Child Abuse Review 12, 279-81.

Beasley, C. 2007: A clear direction. Community Practitioner $80,12,3$.

Bennett, T.H. and Holloway, K.R. 2004: Gang membership, drugs and crime in the UK. British Journal of Criminology 44, 305-23.

Bull, J., McCormick, G., Swann, C. and Mulvihill, C. 2004: Ante- and post-natal home-visiting programmes: a review of reviews. London: Health Development Agency.
Cowley, S. 2001: Health Visitors: family centred public health workers. National Association of Primary Care: Annual Review, 60-63.

Cowley, S. 2007a: A funding model for health visiting: baseline requirements - part 1. Community Practitioner 80, 18-24.

Cowley, S. 2007b: A funding model for health visiting - part 2: impact and implementation. Community Practitioner 80, 24-31.

Cowley, S., Caan, W., Dowling, S. and Weir, H. 2007: What do health visitors do? A national survey of activities and service organisation. Public Health 121, 869-79. doi:10.1016/j.puhe.2007.03.016.

Cowley, S. and Dowling, S. 2007: To examine how health visiting services relate to levels of deprivation or availability of other services in an area, or if other factors are influential. Final report to Burdett Trust for Nursing. Florence Nightingale School of Nursing and Midwifery, King's College London. Retrieved 30 August 2008 from http://www.kcl.ac.uk/ schools/nursing/research/population/deprivation

Department for Children, Schools and Families. 2007: Teenage parents: next steps. Guidance for local authorities and primary care trusts. London: Department for Children, Schools and Families.

Department for Education and Skills. 2002: Every child matters. London: Department for Education and Skills.

Department for Education and Skills and Department of Health. 2004: National service framework for children, young people and maternity service. London: Department of Health.

Department of Health. 2003: Tackling health inequalities: a programme for action. London: Department of Health.

Department of Health. 2006: Health inequalities: revised list of spearhead group primary care trusts. Dear Colleague letter, Gateway reference 7085. London: Department of Health.

Department of Health. 2007a: Review of the health inequalities infant mortality PSA target. Gateway reference 7759. London: Department of Health.

Department of Health. 2007b: The government response to facing the future: a review of the role of health visitors. London: Department of Health.

Department of Health; Department for Children Schools and Families. 2008: Child health promotion programme: pregnancy and the first five years of life. London: Department of Health.

Department of Health. 2008a: The operating framework for 2009/10 for the NHS in England. Gateway Ref 10967. London: Department of Health.

Department of Health. 2008b: Transforming community services: currency and pricing options for community services. Gateway Ref 10846. London: Department of Health.

Department of Health. 2009: Transforming community services and world class commissioning: resource pack for commissioners of community services. Gateway Ref 10846. London: Department of Health. 
Dingwall, R. 1977: Collectivism, regionalism and feminism: health visiting and British social policy 1850-1975. Journal of Social Policy 6, 291-315.

Elkan, R., Robinson, J., Williams, D. and Blair, M. 2000: Universal vs. selective service. The case of the British health visitor. Journal of Advanced Nursing 33, 113-19.

Family and Parenting Institute (FPI). 2007: Health visitors - an endangered species. London: FPI.

Gaynes, B.N., Gavin, N., Meltzer-Brody, S., Lohr, K.N., Swinson, T., Gartlehner, G. et al. 2005: Perinatal depression: prevalence, screening accuracy, and screening outcomes. Evidence Reports: Technology Assessment; 19 AHRQ Publication No. 05-E006-2.

Glass, N. 1999: Sure start: the development of an early intervention programme for young children. Children and Society 13, 257-62.

Health Visitors' Association. 1994: A cause for concern. London: Health Visitors' Association.

HM Government. 2006a: Reaching out: an action plan on social exclusion. London: Cabinet Office, Social Exclusion Task Force.

HM Government. 2006b: Joint planning and commissioning framework for children, young people and maternity services. London: Department for Education and Skills.

HM Government. 2008: Staying safe: an action plan. London: Department for Children, Schools and Families.

HM Treasury, Department for Education and Skills (DfES). 2005: Support for parents: the best start for children. London: HM Treasury.

HM Treasury, Department for Education and Skills (DfES). 2007: Aiming high for children: supporting families. London: HM Treasury.

HM Treasury. 2007: Meeting the aspirations of the British people. Pre-budget report and comprehensive spending review CM 7227. London: Stationery Office.

Hosking, G. and Walsh, I. 2005: Violence and what to do about it: The Wave Report. London: Wave Trust.

Irwin, L., Siddiqi, A. and Hertzman, C. 2007: 'Early child development: a powerful equalizer. Final report to the World health Organization's Commission on Social Determinants of
Health. Retrieved 23 July 2008 from http://www.who.int/ social_determinants/resources/ecd_kn_report_07_2007.pdf

Karoly, L.A., Kilburn, M.R. and Cannon, J.S. 2005: Early childhood interventions: proven results, future promise. Santa Monica, CA: Rand Corporation. http://www.rand.org/

Lowe, R. 2007: Facing the Future: a review of the role of health visitors. London: Department of Health.

Macleod, J. and Nelson, G. 2000: Programs for the promotion of family wellness and the prevention of child maltreatment: a meta-analytic review. Child Abuse and Neglect 24, 1127-49.

The Children Act. 2004: Chapter 31. London: HMSO.

National Statistics. 2004: Indicators of social capital: by gross weekly household income, 2004. Social Trends 34. Retrieved 25 February 2008 from http://www.statistics.gov. $\mathrm{uk} /$ StatBase/ssdataset.asp? $\mathrm{vlnk}=7455 \&$ More $=$ Y

National Statistics. 2007: Infant and perinatal mortality by social and biological factors. Health Statistics Quarterly 36 Winter 2007: 84. http://www.statistics.gov.uk/statbase/ Product.asp?vlnk $=6725$

Office National Statistics. 2008: Population and migration highlights. Retrieved 25 February 2008 from http:// www.statistics.gov.uk/cci/nugget.asp?id=1433

Olds, D.L. 2006: The nurse-family partnership: an evidence based preventive intervention. Infant Mental Health Journal 27, 5-25.

Prime Minister's Strategy Unit. 2005: Improving the lives of disabled people. London: Cabinet Office.

Russell, S. 2008: Left fending for ourselves. A report on the health visiting service as experienced by Mums. Retrieved 19 September 2008 from Netmums: http://www.netmums.com

Shonkoff, J.P. and Phillips, D.A. 2000: From neurons to neighbourhood: the science of early childhood development. Washington, DC: National Academy Press.

Social Exclusion Task Force (SETF), Cabinet Office. 2007: Reaching out: think family. Analysis and themes from the families at risk review. London: Cabinet Office.

The Information Centre. 2008: NHS hospital and community health services non-medical staff England 1997-2007. London: Department of Health. 